\title{
LO ESPIRITUAL Y LO MATERIAL: EL SÍMBOLO DISÉMICO Y EL DESARROLLO DE LA AMBIGÜEDAD EN LA REGENTA DE GLARÍN
}

\section{LA AMBIGÜEDAD ESPÍRITU/MATERIA: ESTADO DE LA CUESTIÓN}

En este trabajo pretendo estudiar cómo evoluciona la ambigüedad espíritu/materia en La Regenta, mediante la descripción comparativa, desde una perspectiva pragmática, entre la torre de la Catedral y don Fermín de Pas. En este sentido, intento demostrar la importancia de la torre y su relación estrecha con Fermín.

Ha sido Laura Núñez de Villavicencio, al estudiar la creatividad en el estilo de Clarín, quien ha intuido con claridad la fusión del espíritu y la materia en la metáfora del autor de $L a$ Regenta, cuando se da cuenta de que

en su mayor parte, el sustrato del sistema metafórico de Alas proviene de una doble visión que abarca mundos dispares y pretende fundirlos en armonía. Y muy numerosas serían las referencias más o menos explícitas que pudieran confirmar esa posición angustiada e indecisa del autor ante una concepción del mundo polarizada entre abstracción y forma, espíritu y materia, Dios y su opuesto (este último término encarnado casi siempre en los conflictos del sexo); y un vivo anhelo, de raíz profundamente religiosa, que busca trascender esa contradicción en unidad ${ }^{1}$.

En cuanto a la ambigüedad en la descripción de la torre, dos investigaciones de 1985 ponen de manifiesto el símbolo disémico. Por una parte, Sergio Beser ha afirmado que

1 La creatividad en el estilo de Leopoldo Alas, “Clarín”, Instituto de Estudios Asturianos, Oviedo, 1974, p. 220. 
las numerosas referencias a la torre de la catedral, esparcidas por la obra, la proyectan hacia una simbolización disémica: por un lado, la elevación, la aspiración a un ideal; por otro - "fantasma gigante que velaba por la ciudad"-, el poder que domina Vetusta, la iglesia católica².

Y, por otra parte, Frank Durand, al referirse a las dimensiones irónicas y estéticas en el estilo de La Regenta, comenta que

esta visión poética, sin embargo, choca con la frase precedente, donde se describe que la torre, a veces "tomaba los contornos de una enorme botella de champaña”... aquí la discrepancia entre la visión romántica de la torre y su descripción como una botella gigantesca deja al lector con impresiones mixtas. El lector que espera fiarse en la autoridad absoluta de la voz narrativa, se da cuenta con estos primeros párrafos que en esta voz se encuentra la ambigüedad de la ironía ${ }^{3}$.

Por último, John Rutherford, que hace hincapié en el lector cómplice, infiere que

la relación entre lo poético espiritual y lo prosaico material, entre torre y calle, no es la de una simple dicotomía de fuerzas contrarias e independientes, como podría dar a suponer una lectura ingenua, y como quisiera hacernos creer el pensamiento romántico, sino la de una intrincada dialéctica de fuerzas contrarias en continua interacción. La torre no se puede librar, en ningún momento, de la influencia de la calle: con sólo vestirla de faroles el cabildo la convierte en una enorme botella de champaña, todo un símbolo de la frivolidad, materialismo y cursilería modernos. Con esto no quiero negar que la torre sea también un símbolo de las aspiraciones espirituales: sí que lo es -no deja de señalar al cielo-, pero no es ni puede ser un símbolo puro ${ }^{4}$.

Sobre la ambigüedad en el Magistral, María del Carmen Bobes Naves ha hecho -entre otras- las siguientes observaciones:

2 "Espacio y objetos en La Regenta", en "Clarín" y su obra. Actas del Simposio Internacional celebrado en Barcelona del 20 al 24 de marzo de 1984, ed. A. Vilanova, Universidad, Barcelona, 1985, p. 217.

3 "Dimensiones irónicas y estéticas en el estilo de La Regenta", en "Clarín" y su obra..., p. 148.

${ }^{4}$ La Regenta y el lector cómplice, Universidad, Murcia, 1988, p. 54. 
1) La ambigüedad que mantiene don Fermín entre las funciones de seductor y de guardián de Ana es paralela a la ambigüedad que observamos en su construcción como personaje.

2) El lector sabe que don Fermín es ambiguo y sabe cuándo utiliza máscara o no, porque lo ve en el discurso novelesco por signos recurrentes ${ }^{5}$.

Por último, Harriet Turner inteligentemente compara la ambigüedad entre la torre y el Magistral de este modo:

El Magistral, personaje doble, se refleja en la dualidad misma de la torre. Desnuda, la torre brinda una grandeza espiritual; vestida, es decir, iluminada por orden del cabildo con faroles de papel y vasos de colores, "perdía", nos advierte Clarín "la inefable elegancia de su perfil y tomaba los contornos de una enorme botella de champaña" (I, 94)... También el Magistral registra esa misma doblez: desnudo, frente al espejo, se ve como hombre íntegro y varonil; vestido, como la torre, de luces y colores -"tornasoles de pluma de faisán" o "cola de pavo real" (I, 118)- sale ya reflejo grotesco de sí mismo, enorme botella de champaña ${ }^{6}$.

\section{EL DESARROLLO DE LA AMBIGÜEDAD ESPÍRITU/MATERIA EN LA TORRE}

Importa, en primer lugar, acudir a la siguiente consideración de S. Beser, referida al espacio y objetos en La Regenta:

El espacio en La Regenta, como en toda novela realista, es una extensión "ocupada", en la que se ha producido una integración

5 Teoría general de la novela. Semiología de "La Regenta", Gredos, Madrid, 1985, pp. 126 y 137. Según Jerónimo VidA, "el mejor carácter de su novela no es el de Ana Ozores, sino el del magistral. Este sí que es un ser vivo, que siente y obra como los hombres de carne y hueso, con sus contradicciones, con sus vehemencias y desfallecimientos, con sus arrebatos y obcecaciones, con sus vicios y sus virtudes. Todo en D. Fermín de Pas está perfectamente estudiado y presentado, y no aparece una vez en aquellas páginas, que no lo haga con tal realce y viveza, que parece como que se le mete por los ojos al lector, cual si tuviera realidad corpórea” (“"Últimas novelas III». La Regenta, de D. Leopoldo Alas", en Clarín y "La Regenta" (1884-1984), eds. A. Amorós y J.M. Martínez Cachero, Ministerio de Cultura y Dirección General del Libro y Bibliotecas, Madrid, 1984, p. 100).

6 "Vetusta: espacio-fuerza en La Regenta", en "Clarín” y su obra..., p. 38. 
entre el espacio como continente y el contenido, del que forman parte series de objetos; algunos de los cuales alcanzan una particular importancia textual, en función de la relación que establecen con los personajes ${ }^{7}$.

En este sentido, en el presente estudio se va a comprobar la importancia de la torre de la Catedral en La Regenta y su relación con Fermín de Pas. Téngase en cuenta, además, que el propio Leopoldo Alas justifica textualmente la relevancia de la torre en dos ocasiones en el capítulo quinto de la primera parte:

Cuando llegaba un forastero, se le enseñaba la torre de la catedral, el Paseo de Verano, y, si era posible, la sobrina de las de Ozores. Eran las tres maravillas de la población ${ }^{8}$.

Un jadiós! llenó los ámbitos de la Plaza Nueva: era un adiós triste de verdad, era la despedida de la maravilla del pueblo; Vetusta en masa veía marchar a la nueva Presidenta de Sala como pudiera haber visto que le llevaban la torre de la catedral, otra maravilla $(R$, t. 1 , cap. 5 , p. 246).

El enunciado con el que se inicia este análisis es el de la primera descripción de la torre de la Catedral, justo al comienzo de la novela ${ }^{9}$ :

La torre de la catedral, poema romántico de piedra, delicado himno, de dulces líneas de belleza muda y perenne, era obra del siglo dieciséis, aunque antes comenzada, de estilo gótico, pero, cabe decir, moderado por un instinto de prudencia y armonía que modificaba las vulgares exageraciones de esta arquitectura.

7 Art. cit., p. 220.

8 Leopoldo Alas "Clarín", La Regenta, ed. G. Sobejano, Castalia, Madrid, 1981, t. 1, cap. 5, p. 224. Cito por esta edición como $R$, seguida de tomo, capítulo y número de página.

9 Para Claudio Guillén, "el prodigioso capítulo primero es una representación, una introducción narrativa de insólita riqueza -difícil sería imaginarse un resumen más completo del escenario de toda una novela, o donde se citen más nombres y describen más lugares o esbocen más temas de fundamental importancia para todo cuanto sigue- $y$ sin embargo el lector no se siente un solo segundo perdido. Hay profusión de vida, pero perfectamente dominada por las dimensiones descriptivas e interpretativas que desde un principio estructuran y jerarquizan ese abundante mundo ficticio" ("Apuntes para un estudio de la diégesis en "La Regenta»", en "Clarín" y su obra..., p. 276). 
La vista no se fatigaba contemplando horas y horas aquel índice de piedra que señalaba al cielo; no era una de esas torres cuya aguja se quiebra de sutil, más flacas que esbeltas, amaneradas, como señoritas cursis que aprietan demasiado el corsé; era maciza sin perder nada de su espiritual grandeza, y hasta sus segundos corredores, elegante balaustrada, subía como fuerte castillo, lanzándose desde allí en pirámide de ángulo gracioso, inimitable en sus medidas y proporciones. Como haz de músculos y nervios la piedra enroscándose en la piedra trepaba a la altura, haciendo equilibrios de acróbata en el aire; y como prodigio de juegos malabares, en una punta de caliza se mantenía, cual imantada, una bola grande de bronce dorado, y encima otra más pequeña, y sobre ésta una cruz de hierro que acababa en pararrayos.

Cuando en las grandes solemnidades el cabildo mandaba iluminar la torre con faroles de papel y vasos de colores, parecía bien, destacándose en las tinieblas, aquella romántica mole; pero perdía con estas galas la inefable elegancia de su perfil y tomaba los contornos de una enorme botella de champaña. Mejor era contemplarla en clara noche de luna, resaltando en un cielo puro, rodeada de estrellas que parecían su aureola, doblándose en pliegues de luz y sombra, fantasma gigante que velaba por la ciudad pequeña y negruzca que dormía a sus pies $(R, \mathrm{t}$. 1 , cap. 1, pp. 93-94).

El autor define la torre de la Catedral por medio de una oración atributiva, en la que interesa sobre todo la expansión del sujeto: poema romántico de piedra, delicado himno, de dulces líneas de belleza muda y perenne. Dos aposiciones predicativas yuxtapuestas. Para el sentido de estas expansiones clarinianas conviene tener en cuenta estas palabras de L. Núñez de Villavicencio:

Esa reiteración explicativa de los conceptos, aparte de su función descriptiva detallista, puede lograr efectos de precisión mediante la gradación comparativa de los diferentes matices de un concepto. En esos casos, la técnica consiste no sólo en desarrollar los elementos de lo que se quiere describir amplificando sus componentes, sino en sopesar comparativamente expresiones casi sinónimas ${ }^{10}$.

En la primera de las anteriores aposiciones (poema romántico de piedra) se distingue el sintagma nominal apositivo de la construcción preposicional modificadora del nombre, ya que hay

10 Op. cit., p. 178. 
una clara intencionalidad por parte del emisor de que se origine un paralelismo entre esta estructura morfosintáctica binaria y la semántica, también binaria. El primer término (poema romántico) identifica lo arquitectónico con lo literario:

la torre de la Catedral = poema romántico.

Se hace referencia a un período concreto de la historia de la literatura: el Romanticismo. Sin embargo, la construcción preposicional (de piedra) incluye rasgos propios del campo de la arquitectura. Para María Cruces Morales Saro,

expresiones como "poema romántico de piedra" nos conducen a esa interferencia de lo literario y lo plástico y también hacia un indudable aprecio de lo medieval siempre que el gótico esté "moderado por un instinto de prudencia y armonía" que consiga obviar "las vulgares exageraciones de esa arquitectura"

Son, en realidad, dos términos antagónicos, de los que se obtienen implicaturas opuestas: poema romántico hace referencia a 'lo espiritual', mientras que de piedra remite a 'lo material'. Esta oposición entre espíritu y materia va a ser la característica más relevante en la que voy a basar mi investigación, porque es el argumento más poderoso: en esta descripción Clarín está personificando la torre ${ }^{12}$. Todavía más, la torre de la Catedral es el primer personaje de su novela. En este sentido, C. Guillén ha afirmado que la torre "es materia, pero tan admirable que sugiere o implica espíritu" 13 .

La personificación de la torre continúa en todas las adjetivaciones metafóricas. La segunda aposición, también segunda metáfora, identifica el sujeto (la torre de la catedral) con delicado himno, de dulces líneas de belleza muda y perenne. Ahora, la relación

11 "Crítica de la arquitectura y urbanismo en La Regenta", en Clarín y "La Regenta" en su tiempo. Actas del Simposio Internacional celebrado en Oviedo en 1984, Universidad, Oviedo, 1987, p. 697.

12 Según F. Durand, "son las imágenes, especialmente la personificación, las que crean el tono de la escena al establecer la perspectiva narrativa. Así recalca la importancia de la temática y la acción" (art. cit., p. 146). Y, más adelante, el mismo autor afirma que "las repetidas personificaciones de la catedral, la torre y el reloj tienen un papel estructural y un efecto dramático determinado por el valor expresivo y subjetivo de la personificación” (p. 152).

13 Art. cit., p. 275. 
se establece entre el mundo de la arquitectura, la poesía y el de la música:

la torre de la Catedral = delicado himno.

Este sintagma nominal (delicado himno) es el componente espiritual de la metáfora, ya que las construcciones preposicionales siguientes hacen referencia al elemento material de la misma (de belleza muda y perenne), lo propiamente arquitectónico. Por otra parte, himno puede establecer relaciones tanto con lo musical como con lo poético, partes esenciales del espíritu. La anteposición de los adjetivos delicado y dulces guarda una evidente relación con esta descripción literaria subjetiva: el objeto torre (personaje literario) se describe desde la perspectiva íntima de Clarín. Las posposiciones de los adjetivos muda y perenne funcionan a modo de intensificadores del elemento material ( $l a$ piedra). En cuanto a esta perspectiva íntima de Leopoldo Alas, L. Núñez de Villavicencio ha afirmado que

es más bien en sus contenidos y en sus relaciones con las palabras modificadas donde radica la fuerza expresiva de la adjetivación clariniana. Los elementos recogidos de la realidad aparecen impregnados en su prosa de cualidades morales, o de sentimientos abstractos de acuerdo a la visión anímica fuertemente emotiva del autor ${ }^{14}$.

Asimismo, al referirse al estilo gótico, se sirve del operador argumentativo pero para contrarrestar lo negativo de este estilo arquitectónico: "moderado por un instinto de prudencia y armonía que modificaba las vulgares exageraciones de esta arquitectura". Instinto de prudencia y armonía forma parte de la faceta inmaterial. Estos dos sustantivos (prudencia y armonía) se oponen semánticamente a los dos adjetivos anteriores (muda y perenne).

Una vez que Clarín ha definido la torre, a continuación la contempla y al mismo tiempo la describe (La vista no se fatigaba contemplando horas y horas aquel índice de piedra que señalaba al cielo). La primera parte de este término metafórico (sintagma nominal + construcción preposicional) hace alusión al elemento material, mientras que la proposición adjetiva alude a lo espiritual. Nótese cómo la piedra se repite en este mismo enunciado: como haz de músculos y nervios la piedra enroscándose en la piedra

${ }^{14}$ Op. cit., pp. 62-63. 
trepaba a la altura, así como en estos otros enunciados a lo largo de la novela:

La torre de la catedral, que a la luz de la clara noche se destacaba con su espiritual contorno, transparentando el cielo con sus encajes de piedra ( $R$, t. 1, cap. 10, pp. 377-378).

La torre de la catedral allá arriba, como en la cúspide de un monumento, encaje de piedra obscura sobre fondo de naranja y de violeta de un cielo suave, listado, de nubes largas, estrechas, ondeadas, quietas sobre el abismo, como esperando a que se acostara el sol para cerrar el horizonte... ( $R$, t. 2, cap. 19, p. 128).

Y separando los ojos "de aquella podredumbre en fermento, de aquella gusanera inconsciente", volviólos Guimarán a lo alto, y miró a la torre que con un punto de luz roja señalaba al cielo... "¡Aquí no hay nada cristiano, pensó, más que ese montón de piedras!" $(R$, t. 2, cap. 26, p. 340).

La piedra es, por tanto, el elemento material por excelencia, definitivo en Clarín, para precisar la parte material de la torre, como puede comprobarse en el enunciado del capítulo once en el que el autor compara explícitamente a don Fermín con la torre:

Se parecía un poco a su querida torre de la catedral, también robusta, también proporcionada, esbelta y bizarra, mística; pero de piedra ( $R$, t. 1, cap. 11, p. 410).

En esta conclusión del propio autor se opone piedra a robusta, proporcionada, esbelta, bizarra y mística. De este modo, estas son las variantes sintagmáticas en las que se encuentra el sustantivo piedra: índice de piedra, la piedra enroscándose en la piedra, encajes de piedra, encaje de piedra y montón de piedras. Es decir, desde indicio o señal de piedra, a la utilización del gerundio enroscándose, de valor plenamente durativo imperfectivo y la explicatura de 'trabajo perfecto' hasta montón. Se observa, por tanto, en la descripción una gradación desde las connotaciones positivas hasta las negativas.

Clarín continúa su argumentación discursiva sirviéndose de diferentes estructuras morfosintácticas, en las que sigue uniendo lo material a lo espiritual. De este modo, la siguiente adjetivación se ajusta a la estructura 'sintagma adjetival + proposición 
adverbial-circunstancial de modo' (maciza sin perder nada de su espiritual grandeza $)^{15}$. El adjetivo es la materia; la proposición, lo espiritual. Además, dicha estructura morfosintáctica se inserta en un grupo oracional por coordinación adversativa: no era una de esas torres..., era maciza... La primera oración adversativa actúa como intensificador de lo dicho en la segunda oración, al oponer el adjetivo maciza a los adjetivos sutil, flacas, amaneradas y cursis. L. Núñez de Villavicencio lo explica así:

La precisión del calificativo exacto para tan inmaterial sujeto se busca por un procedimiento eliminatorio: no era una de esas, apoyado por la reiteración de imágenes cognadas que constituyen anticipos o aproximaciones del refinado ajuste semántico que el autor se propone: indice de piedra, aguja que se quiebra de sutil. La distinción entre los significados calificativos flacasy esbeltas se hace cuantitativa y estricta mediante la fórmula comparativa "más... que". La noción así evocada resulta intermedia y, eficazmente subrayada por el pictórico símil como señoritas cursis que aprietan demasiado el corsé, constituye por vía negativa otra aproximación, que culmina en la declaración final: era maciza inimitable en sus medidas y proporciones $^{16}$.

La comparación es otro recurso del que se sirve el autor para definir la torre: "como haz de músculos y nervios la piedra enroscándose en la piedra trepaba a la altura" y "subía como fuerte castillo". Núñez de Villavicencio ha comentado que este recurso "más bien obedece a las necesidades técnicas del procedimiento narrativo, que por su propia naturaleza se aviene mejor a los símiles que a las metáforas puras" (p. 223). En la primera de las comparaciones anteriores la personificación se hace patente en la metáfora haz de músculos y nervios (humanización de la torre), al tiempo en que se hace presente la explicatura de 'fortaleza'. El elemento material se intensifica, ya que ejerce las funciones de sujeto y complemento circunstancial de una proposición de gerundio: la piedra enroscándose en la piedra. Además, el gerundio con valor aspectual durativo es un intensificador más de la materia. Y de nuevo la altura como elemento espiritual: trepaba a la altura.

15 M.C. Morales Saro comenta que cuando Clarín enumera "las características arquitectónicas que considera positivas: maciza, de inimitables proporciones, está aplicando una terminología cuasi vitrubiana, no muy apta para describir al gótico" (art. cit., p. 697).

16 Op. cit., pp. 179-180. 
En la segunda comparación, la forma verbal personifica la elevación (lo espiritual), mientras que el segundo término comparativo se relaciona con la materia (la piedra). Del mismo modo, en bola grande de bronce dorado y cruz de hierro, el bronce y el hierro se identifican con la materia; y lo dorado y la cruz con lo espiritual. Sin embargo, "cuando en las grandes solemnidades el cabildo mandaba iluminar la torre con faroles de papel y vasos de colores" ( $R$, t. 1, cap. 1, p. 94), la torre se convertía en una romántica mole y en una enorme botella de champaña. Es decir, lo que antes era poema romántico ahora es romántica mole. Contrastan las connotaciones positivas de la descripción inicial con las negativas del final de este enunciado. Sobre este contraste, S. Beser ha hecho el siguiente comentario:

Y cuando los elementos descriptivos parecen apartarse de la negatividad valorativa -la torre de la catedral "poema romántico de piedra, delicado himno, de dulces líneas de belleza muda y perenne..."- inmediatamente, en un procedimiento usual en la lengua literaria de "Clarín", aparecerá la referencia destructora de la elevación cuantitativa: la torre, "índice de piedra que señalaba al cielo", es convertida, por sus dueños, el cabildo, en enorme botella de champaña ${ }^{17}$.

La torre es espiritual en su estado natural. Sin embargo, su aspecto externo, con faroles de papel y vasos de colores, la convierte en un objeto material. Y en esta estructura argumentativa el agente es el Cabildo, la Iglesia. La oposición espíritu/materia es tal que Clarín no sólo establece contrastes con la descripción anterior, sino que cierra este enunciado con una descripción de connotaciones positivas: "Mejor era contemplarla en clara noche de luna, resaltando en un cielo puro, rodeada de estrellas que parecían su aureola, doblándose en pliegues de luz y sombra" ( $R$, t. 1, cap. 1, p. 94). De este modo, enorme botella de champaña se opone a clara noche de luna, cielo puro, estrellas, aureola, luz y sombra, elementos todos que constituyen el término real de la metáfora apositiva fantasma gigante, cuyo término adyacente (que velaba por la ciudad pequeña y negruzca que dormía a sus pies) se opone a espiaba, como Clarín afirma:

La torre de la catedral, que espiaba a los interlocutores de la glorieta desde lejos, entre la niebla que empezaba a subir por aquel

${ }^{17}$ Art. cit., p. 217. 
lado, dejó oír tres campanadas como un aviso. Le parecía que ya habían hablado bastante $(R$, t. 2, cap. 17, p. 73).

Se comprueba, una vez más, el simbolismo disémico con el que Clarín describe la torre de la Catedral. Esta imagen, la de fantasma gigante, se repite con variación adjetival en el capítulo diez de la primera parte:

La torre de la catedral, que a la luz de la clara noche se destacaba con su espiritual contorno, transparentando el cielo con sus encajes de piedra, rodeada de estrellas, como la Virgen en los cuadros, en la obscuridad ya no fue más que un fantasma puntiagudo; más sombra en la sombra ( $R$, t. 1, cap. 10, pp. 377-378).

La gradación connotativa ha llegado a su punto final (fantasma puntiagudo; sombra en la sombra). De 'muy grande' se pasa a 'punzante', 'afilado'; y de luz y sombra a sombra en la sombra. Otras metáforas, símbolo de muerte, son mástil sumergido y gallardete negro:

La torre de la catedral aparecía a lo lejos, entre la cerrazón, como un mástil sumergido ( $R$, t. 2, cap. 18, p. 83).

“;Soy un miserable, soy un miserable!” gritaba por dentro Quintanar mientras el tren volaba y Vetusta se quedaba allá lejos; tan lejos, que detrás de las lomas y de los árboles desnudos ya sólo se veía la torre de la catedral, como un gallardete negro destacándose en el fondo blanquecino de Corfín, envuelto por la niebla que el sol tibio iluminaba de soslayo ( $R$, t. 2, cap. 29, p. 478).

Se trata de enunciados de la segunda parte de la novela, en los que la torre es símbolo de muerte.

Todo este recorrido pone de manifiesto que, realmente, en la primera parte de la novela la torre es un símbolo disémico. Se comprueba, por tanto, que la torre de la Catedral de Vetusta -como símbolo ambiguo- ha inspirado a Leopoldo Alas un complejo conjunto de metáforas y símiles, en el que se aúna perfectamente lo material y lo espiritual. Clarín, justo al comienzo de La Regenta, lleva a cabo una completa descripción de la torre. Sin embargo, a lo largo de la novela, sí se observa una gradación en cuanto a la evolución de la ambigüedad del símbolo. En las primeras metáforas apositivas (poema romántico de piedra, delicado himno), se yuxtapone el espíritu a la materia. Asimismo, se 
presenta una imagen física espiritualizada (aquel índice de piedra que señalaba al cielo). Por otra parte, el carácter humano de la torre se evidencia en una comparación de clara naturaleza física (como haz de músculos y nervios), así como la materialización total (enorme botella de champaña). Sin embargo, la torre es un símbolo tan disémico que lo mismo se ve como imagen sagrada (rodeada de estrellas que parecían su aureola) que como una imagen confusa e inquietante (fantasma gigante), pero sin dejar de estar rodeada de estrellas como la Virgen en los cuadros y sin dejar de ser más que un fantasma puntiagudo.

Después del primer capítulo de la primera parte de la novela, la torre se describe en el cap. 10, donde Clarín vuelve a insistir en su ambigüedad: espiritual contorno y rodeada de estrellas, como la Virgen en los cuadros vs. encajes de piedra y fantasma puntiagudo, sombra en la sombra. Por el contrario, en la segunda parte de la novela, se pierde la ambigüedad y la torre es mástil sumergido, encaje de piedra obscura, montón de piedras y gallardete negro. La torre de la Catedral, por tanto, ya sólo es materia.

\section{EL DESARROLLO DE LA AMBIGÜEDAD MATERIA/ESPÍRitu EN FERMín de PAS}

Conviene, en primer lugar, poner de manifiesto el acertado comentario de Biruté Ciplijauskaité, cuando afirma que, aunque La Regenta es una novela de protagonista colectivo, "no por eso deja de ahondar en conflictos individuales, creando la compleja figura de don Fermín" ${ }^{18}$. Es, también, al principio de la novela y después de la descripción de la torre, cuando Clarín a través de Bismarck hace la primera caracterización del Magistral: "un personaje de los más empingorotados"19 $(R$, t. 1, cap. 1 ,

18 “Don Fermín, ¿anti-modelo de don Magín?", Actas del VII Congreso de la Asociación Internacional de Hispanistas (Venecia, 1980), ed. G. Bellini, Bulzoni, Roma, 1982, t. 1, p. 307. Asimismo, José OrTegA afirma que "en la figura del cura Fermín lleva a cabo Leopoldo Alas un profundo análisis del mundo anímico de este personaje cuya complejidad psicológica está más allá de cualquier determinismo conductista" ("Don Fermín de Pas: un estudio 'de superbia et concupiscentia catholicis', Revista de Estudios Hispánicos, 9, 1975, núm. 3, p. 323).

${ }^{19}$ Alas vuelve a utilizar este adjetivo pocas páginas más adelante: "Cuando iba a las aldeas acompañando al Obispo en su visita, siempre había de emprender, a pie o a caballo, como se pudiera, una excursión a lo más empingorotado" ( $R$, t. 1, cap. 1, p. 104). 
p. 99). Es decir, se trata de una persona que había adquirido una posición social elevada y se engreía de ello. Esta caracterización inicial tiene, por tanto, connotaciones negativas. Sin embargo, téngase en cuenta que se trata de una caracterización externa y hecha desde la perspectiva de otro personaje. Sin embargo, para nuestro estudio más relevante va a ser el recuerdo de Celedonio: "Celedonio no extrañaba aquella visita. Recordaba haber visto muchas tardes al señor Magistral subir a la torre antes o después de coro" ( $R$, t. 1, cap. 1, p. 100). De este modo, desde el comienzo de la novela se pone de manifiesto la relación entre Fermín de Pas y la torre. Además, la capilla del Magistral estaba junto a la puerta de la torre:

Glocester salía siempre por la puerta del claustro, abierta al extremo Norte del crucero; por allí llegaba antes a su casa: pero esta vez quiso salir por la puerta de la torre, porque así pasaba junto a la capilla del Magistral ( $R$, t. 1, cap. 2, p. 153).

Otra caracterización más, desde la perspectiva de Celedonio, es la que proporciona el adjetivo grande: "Aquel don Fermín que allá abajo en la calle de la Rúa parecía un escarabajo ¡qué grande se mostraba ahora a los ojos humillados del monaguillo y a los aterrados ojos de su compañero!" ( $R$, t. 1, cap. 1, p. 101). El emisor juega con el contraste entre la apariencia (escarabajo) y el estado real (grande), así como las oposiciones entre este último adjetivo y humillados y aterrados. De esta caracterización física inferimos la caracterización moral del personaje: el poder material de Fermín de Pas. Pérez Galdós, en el prólogo a la segunda edición de La Regenta ${ }^{20}$, advierte que Clarín comienza su obra con la figura culminante del Magistral, "personalidad grande y compleja, tan humana por el lado de sus méritos físicos, como el de por sus flaquezas morales, que no son flojas, bloque arrancado de la realidad" (p. 86).

En cuanto a la descripción clariniana de don Fermín, Bobes Naves ha escrito que Alas

lo va diseñando con trazos poco precisos, borrosos, tanto en su físico como en su carácter. Es una especie de visión calidoscópica del Magistral, que se mantendrá a lo largo de la novela, y que obligará al lector a estar pendiente de todo lo que se diga sobre él. El

20 "Prólogo a La Regenta de Leopoldo Alas «Clarín»", en La Regenta, ed. cit., t. 1, pp. 79-92; fechado en Madrid, enero de 1901. 
narrador no lo presenta nunca con trazo seguido, sino con una técnica de puntos que es preciso ordenar y poner en coherencia para entenderlo, e incluso a veces, borrar partes ${ }^{21}$.

De la descripción de la expresión de la cara ya se infiere una cierta ambigüedad en el personaje:

Si los pilletes hubieran osado mirar cara a cara a don Fermín, le hubieran visto, al asomar en el campanario, serio, cejijunto; al notar la presencia de los campaneros levemente turbado, y en seguida sonriente, con una suavidad resbaladiza en la mirada y una bondad estereotipada en los labios ( $R$, t. 1, cap. 1, p. 102).

La oposición entre su estado natural y el de la apariencia se hace evidente a través de una gradación semántica del adjetivo:

serio - cejijunto - turbado - sonriente.

El operador argumentativo (en seguida), junto con los adjetivos resbaladiza y estereotipada son tres argumentos de la ironía subyacente en este enunciado. De este modo, se infiere que Fermín de Pas es, realmente, serio y cejijunto. La ambigüedad, por tanto, desaparece tras el descubrimiento de la ironía. En este sentido, para Frances Wyers Weber,

lo que se pone de manifiesto no es la deseada individualidad de espíritu y materia, sino la carencia de espíritu del mundo moderno [...] Los románticos buscaron la armonía de la sensualidad y del espíritu; Alas, al tomar el camino indirecto de la ironía, muestra la falta de armonía de lo que debiera ser un único todo. Los contrarios se reconcilian, líricamente en un caso, satíricamente en el otro ${ }^{22}$.

Y tras la ironía clariniana se infiere la explicatura de 'falso', como característica psicológica del personaje. Igual ocurre con el color de la cara:

Tenía razón el delantero. De Pas no se pintaba. Más bien parecía estucado. En efecto, su tez blanca tenía los reflejos del estuco. En los pómulos, un tanto avanzados, bastante para dar energía

21 Op. cit., p. 128. p. 128.

22 "Anticlericalismo y religiosidad", en Clarín y "La Regenta" (1884-1984), 
y expresión característica al rostro, sin afearlo, había un ligero encarnado que a veces tiraba al color del alzacuello y de las medias. No era pintura, ni el color de la salud, ni pregonero del alcohol; era el rojo que brota en las mejillas al calor de palabras de amor o de vergüenza que se pronuncian cerca de ellas, palabras que parecen imanes que atraen el hierro de la sangre. Esta especie de congestión también la causa el orgasmo de pensamientos del mismo estilo ( $R$, t. 1, cap. 1, p. 102).

Del color blanco del estuco se pasa al rojo que brota en las mejillas. Ahora el argumento de que el color va más allá de lo físico es que "De Pas no se pintaba". Y nuevamente la gradación semántica característica en el estilo de Alas:

estucado - encarnado - rojo.

Un rojo que, poco a poco, va a ir adquiriendo relevancia en la novela. Por ejemplo, en este primer capítulo Clarín afirma que "entonces sí que en sus mejillas había fuego y en sus ojos dardos" ( $R$, t. 1, cap. 1, p. 104). Y que

el Magistral había sido pastor en los puertos de Tarsa ¡y era él, el mismo que ahora mandaba a su manera en Vetusta! En este salto de la imaginación estaba la esencia de aquel placer intenso, infantil y material que gozaba De Pas como un pecado de lascivia (R, t. 1 , cap. 1 , p. 108$)$.

Por lo tanto, tras ese rojo que brota en las mejillas se infiere la explicatura de que ‘el Magistral era un lascivo'. Para Jo Labanyi, en las primeras páginas de la novela "Vetusta se nos describe a través de la mirada panóptica -mirada a la vez lasciva y autoritaria-del Magistral"23.

La técnica caleidoscópica continúa en la descripción de los ojos:

En los ojos del Magistral, verdes, con pintas que parecían polvo de rapé, lo más notable era la suavidad de liquen; pero en ocasiones, de en medio de aquella crasitud pegajosa salía un resplandor

23 "La Regenta y los discursos de la modernidad", en Leopoldo Alas. Un clásico contemporáneo (1901-2001). Actas del Congreso en Oviedo (12-16 de noviembre de 2001), eds. A. Iravedra Valea, E. de Lorenzo Álvarez y A. Ruiz de la Peña, Universidad, Oviedo, 2002, p. 342. 
punzante, que era una sorpresa desagradable, como una aguja en una almohada de plumas ( $R$, t. 1 , cap. 1, p. 102).

La oposición se establece, a través del operador argumentativo pero, entre la suavidad de liquen y un resplandor punzante. El símil actúa como intensificador semántico, que establece relaciones significativas con la oposición anterior:

suavidad de liquen/resplandor punzante

almohada de plumas/aguja.

Es posible que este enunciado no sea irónico, pero sí, ambiguo. De los dos términos antagónicos prevalece el segundo como verdadero: el primero era sólo apariencia ${ }^{24}$. En cuanto a estas contradicciones, Bobes Naves ha afirmado que

es una técnica, semejante a la que siguen los pintores puntillistas, que exige al lector un alejamiento para ver las figuras. Los informes son discontinuos (en esto no hay diferencia respecto al diseño que la novela sigue para los personajes en general), pero, respecto a don Fermín, son diversos y hasta contradictorios y, por tanto, no pueden interpretarse en forma unívoca y fija, sino en relación con otros, por suma o por contraste. Resulta muy difícil que sobre un personaje así diseñado haya acuerdo para interpretarlo y efectivamente del señor Magistral se han hecho muchas "lecturas"25.

La descripción en la que mejor se funde el espíritu y la materia forma parte, también, de este primer capítulo ${ }^{26}$ :

24 En cuanto a la descripción que lleva a cabo Clarín de la cara extraordinaria de Fermín de Pas, Nö̈L Valis afirma que "un número de rasgos en esta descripción sobresaliente contribuye a la impresión abrumadora de lo desnaturalizado y de lo corrupto en una naturaleza potente pero malévola" ("Fermín de Pas: una Flor del mal clariniana", Explicación de Textos Literarios, 7 (1978), núm. 1, p. 32.

25 Op. cit., pp. 128-129.

26 "Sin precisar de una forma exhaustiva, podemos comprobar que don Fermín es la figura central, y casi exclusiva, del capítulo primero, del segundo y de los cinco que van del undécimo al decimoquinto. En todos ellos la narración se enfoca hacia o desde don Fermín. El ambiente de la catedral en los dos primeros capítulos se manifiesta en torno a la figura del canónigo" (p. 127). 
Uno de los recreos solitarios de don Fermín De Pas consistía en subir a las alturas. Era montañés, y por instinto buscaba las cumbres de los montes y los campanarios de las iglesias. En todos los países que había visitado había subido a la montaña más alta, y si no las había, a la más soberbia torre. No se daba por enterado de cosa que no viese a vista de pájaro, abarcándola por completo y desde arriba. Cuando iba a las aldeas acompañando al Obispo en su visita, siempre había de emprender, a pie o a caballo, como se pudiera, una excursión a lo más empingorotado. En la provincia, cuya capital era Vetusta, abundaban por todas partes montes de los que se pierden entre nubes; pues a los más arduos y elevados ascendía el Magistral, dejando atrás al más robusto andarín, al más experto montañés. Cuanto más subía más ansiaba subir; en vez de fatiga sentía fiebre que les daba vigor de acero a las piernas y aliento de fragua a los pulmones. Llegar a lo más alto era un triunfo voluptuoso para De Pas. Ver muchas leguas de tierra, columbrar el mar lejano, contemplar a sus pies los pueblos como si fueran juguetes, imaginarse a los hombres como infusorios, ver pasar un águila o un milano, según los parajes, debajo de sus ojos, enseñándole el dorso dorado por el sol, mirar las nubes desde arriba, eran intensos placeres de su espíritu altanero, que De Pas se procuraba siempre que podía. Entonces sí que en sus mejillas había fuego y en sus ojos dardos. En Vetusta no podía saciar esta pasión; tenía que contentarse con subir algunas veces a la torre de la catedral. Solía hacerlo a la hora del coro, por la mañana o por la tarde, según le convenía. Celedonio que en alguna ocasión, aprovechando un descuido, había mirado por el anteojo del Provisor, sabía que era de poderosa atracción ( $R$, t. 1, cap. 1, p. 104).

Éste es el enunciado de la irrefrenable ascensión. Cuando Clarín afirma que uno de los recreos solitarios de don Fermín De Pas consistía en subir a las alturas, pone de manifiesto un hecho íntimo y, por tanto, describe una característica psicológica del personaje. En principio, del hecho de subir a las alturas se infiere espiritualidad, lo que guarda relación con la profesión religiosa de don Fermín. Sin embargo, inmediatamente el destinatario percibe una cierta ambigüedad cuando, a continuación, lee el argumento del emisor: Era montañés, y por instinto buscaba las cumbres de los montes y los campanarios de las iglesias. Este argumento, sobre todo el operador argumentativo por instinto contradice la inferencia anterior. La elevación espiritual queda todavía más mitigada, cuando Alas afirma que "no se daba por enterado de cosa que no viese a vista de pájaro, abarcándola por completo y desde arriba”. La explicatura de la proposición de gerundio (abarcándola por completo) 
es 'dominación', 'posesión', significado que se contradice con el desinterés de lo espiritual. Aquí, sí que puede afirmarse un rasgo material de su carácter: la dominación. Para Segundo Serrano Poncela la caracterización de don Fermín de Pas es

lo más logrado de la novela -más que Ana- y muestra el propósito de Alas de hacerle, con ella, soporte principal del conflicto... Junto a la llamada del apetito erótico opera, simultáneamente, su pasión de dominio de modo que Ana Ozores significa para él la conquista de lo inaccesible dentro del derecho y ya conquistado perímetro en que se mueve... Intuimos que pasado el trance que tanto le decepciona, don Fermín proseguirá su carrera de ambiciones hallando para ella nuevos estímulos; seguirá siendo el temido Magistral que aspira al obispado y al cardenalato y Ana Ozores quedará relegada en su memoria como un incidente desapacible ${ }^{27}$.

Por otra parte, conviene traer aquí la observación de J. Rutherford sobre la dominación ejercida por don Fermín:

Al principio don Fermín aparece como un ser acostumbrado a ejercer una dominación total sobre sí y sobre Vetusta. Su presentación en el campanario y toda esa afición suya por las alturas -montañas, torres, púlpitos, balcones-, pueden leerse como un símbolo: vemos a don Fermín como el dueño de la ciudad, un señor feudal que contempla sus dominios... Pero poco a poco, y sobre todo en el segundo tomo, sus relaciones con Ana minan su dominio de sí y de otros ${ }^{28}$.

Dicho carácter posesivo se confirma en otros lugares de la descripción clariniana, como por ejemplo en las páginas siguientes de la novela:

Mientras el acólito hablaba así, en voz baja, a Bismarck que se había atrevido a acercarse, seguro de que no había peligro, el Magistral, olvidado de los campaneros, paseaba lentamente sus miradas por la ciudad escudriñando sus rincones, levantando con la imaginación los techos, aplicando su espíritu a aquella inspección minuciosa, como el naturalista estudia con poderoso microscopio las pequeñeces de los cuerpos. No miraba a los campos, no contemplaba la lontananza de montes y nubes; sus miradas no salían de la ciudad.

27 “Don Fermín de Pas", en Clarín y "La Regenta" (1884-1984), p. 193.

28 Op. cit., p. 115. 
Vetusta era su pasión y su presa. Mientras los demás le tenían por sabio teólogo, filósofo y jurisconsulto, él estimaba sobre todas su ciencia de Vetusta. La conocía palmo a palmo, por dentro y por fuera, por el alma y por el cuerpo, había escudriñado los rincones de las conciencias y los rincones de las casas. Lo que sentía en presencia de la heroica ciudad era gula; hacia su anatomía, no como el fisiólogo que sólo quiere estudiar, sino como el gastrónomo que busca los bocados apetitosos; no aplicaba el escalpelo sino el trinchante ( $R$, t. 1 , cap. 1, pp. 105-106).

El aspecto imperfectivo-durativo continúa en otras proposiciones adverbiales de gerundio: escudriñando sus rincones, levantando con la imaginación los techos, aplicando su espíritu a aquella inspección minuciosa; así como mediante otros recursos lingüísticos como el operador argumentativo lentamente: paseaba lentamente sus miradas por la ciudad. Todo esto es materia. Y Alas lo argumenta por completo: No miraba a los campos, no contemplaba la lontananza de montes y nubes; sus miradas no salian de la ciudad. No se trata, por tanto, de una mirada espiritual. El afecto desordenado de su ánimo y el hecho de tener bien cogida a la ciudad (Vetusta era su pasión y su presa) ponen de manifiesto el carácter material del personaje: la imagen de la gula lo define perfectamente. Si anteriormente se afirma que Vetusta era su presa, en las siguientes líneas leemos:

Cuando estas ideas le sobrecogían, para vencerlas y olvidarlas se entregaba con furor al goce de lo presente, del poderío que tenía en la mano; devoraba su presa, la Vetusta levítica, como el león enjaulado los pedazos ruines de carne que el domador le arroja (R, t. 1 , cap. 1 , p. 106).

Con este símil del león enjaulado Clarín traza con suma expresividad el carácter material del personaje. E insiste, una vez más, en la idea de Vetusta como presa:

Don Fermín contemplaba la ciudad. Era una presa que le disputaban, pero que acabaría de devorar él solo. ¡Qué! ¿También aquel mezquino imperio habían de arrancarle? No, era suyo. Lo había ganado en buena lid ( $R$, t. 1, cap. 1, p. 107).

Esta compleja caracterización psicológica del personaje la explica J. Ortega así: 
En la figura del Magistral, Clarín profundiza en el carácter de la experiencia religiosa de este prelado, no en su concepción teológica. El problema de este cura radica en el hecho de que no ha logrado -ni lo logra a través de la obra-alcanzar su individualización o totalidad psíquica. La religión es un escapismo o sublimación de su instinto sexual (Freud), así como un instrumento de su obsesiva ansia de dominación (A. Adler). Los rasgos más acusados de su personalidad -orgullo, sexo-, así como su relación con las dos mujeres que lo dominan -su madre y Ana- pueden ayudarnos a entender las neurosis y psicosis de este singular tipo ${ }^{29}$.

En el enunciado que he denominado 'de la irrefrenable ascensión', Clarín sigue una estructura argumentativa por medio de un procedimiento deductivo: conclusión - argumentos. A la conclusión inicial (Uno de los recreos solitarios de don Fermín De Pas consistía en subir a las alturas) le siguen seis argumentos:

A1: Era montañés... campanarios de las iglesias

A2: En todos los países que había visitado... a la más soberbia torre

A3: No se daba por enterado... desde arriba

A4: Cuando iba a las aldeas... a lo más empingorotado

A5: En la provincia... al más experto montañés

A6: Cuanto más subía... a los pulmones.

A esta concatenación argumentativa sigue la segunda conclusión, más relevante que la primera, porque carece de ambigüedad: Llegar a lo más alto era un triunfo voluptuoso para De Pas. Esta complacencia en los deleites sensuales elimina cualquier atisbo de espiritualidad, lo que era ambiguo en la conclusión primera. Los argumentos siguientes insisten en el carácter material de la segunda conclusión:

A1: Ver muchas leguas de tierra

A2: columbrar el mar lejano

A3: contemplar a sus pies los pueblos como si fueran juguetes

A4: imaginarse a los hombres como infusorios

A5: ver pasar un águila... dorso dorado por el sol

A6: mirar las nubes desde arriba.

Todos estos sujetos se unen al predicado eran intensos placeres de su espíritu altanero, en el que se reitera la conclusión anterior: "triunfo voluptuoso = intensos placeres de su espíritu altanero".

${ }^{29}$ Art. cit., p. 330. 
El paralelismo no sólo es semántico, con el que se insiste en el carácter material del Magistral, sino también morfosintáctico a través de una estructura atributiva: sujeto + núcleo + atributo. De este modo, todos los recursos lingüísticos se ponen al servicio de la unidad temática.

A continuación una tercera conclusión (Entonces sí que en sus mejillas habia fuego y en sus ojos dardos) pone de manifiesto la correspondencia, anteriormente comentada, entre lo físico y lo moral. Y la segunda parte de esta tercera conclusión (En Vetusta no podía saciar esta pasión; tenía que contentarse con subir algunas veces a la torre de la catedral) evidencia una vez más la relación que a lo largo de toda la novela va a establecer Alas entre Fermín de Pas y la torre de la Catedral. Es en este enunciado ( $R$, t. 1, cap. 1, p. 104) donde Clarín traza a la perfección la psicología del personaje. En las páginas siguientes se insiste en estas mismas características. Por ejemplo, en que la ambición era un estado natural de su carácter:

Y bastante resignación era contentarse, por ahora, con Vetusta... era el hambre que no espera, la sed en el desierto que abrasa y se satisface en el charco impuro sin aguardar a descubrir la fuente que está lejos en lugar desconocido ( $R$, t. 1, cap. 1, p. 106).

En este enunciado, Alas describe la ambición del Magistral (aquellos brillantes cuadros que la ambición había pintado en su fantasía) en su juventud. La fuerza pragmática reside en los operadores argumentativos bastante, por ahora y aún. De la afirmación de que bastante resignación era contentarse, por ahora, con Vetusta se infiere que la identificación hecha anteriormente entre Vetusta y presa forma parte de una ambición mínima, comparada con la ambición inicial de su juventud. De este modo, desaparece la ambigüedad implícita en Uno de los recreos solitarios de don Fermín De Pas consistía en subir a las alturas $(R, \mathrm{t} .1$, cap. 1 , p. 104), ya que la ascensión conlleva una dosis alta de 'ambición'. Estos tres operadores argumentativos son intensificadores de esa cualidad moral del personaje. Por lo tanto, en ese subir a las alturas sólo hay materia. Y, si se tiene en cuenta que la codicia del poder era más fuerte y menos idealista, nos topamos sin remedio con la materia. Materia, que Clarín ha descrito con toda su intensidad:

Lo quería con más fuerza

Lo necesitaba más cerca 
El hambre que no espera

La sed en el desierto que abrasa y se satisface en el charco impuro.

Estos son actos de habla ilocutivos directos en los que se da una perfecta correspondencia entre acto de habla y forma lingüística. La ambición es tal que la realidad del momento presente queda asociada a un sueño del pasado:

Desde aquella infancia ignorante y visionaria al momento en que se contemplaba el predicador no había intervalo; se veía niño y se veía Magistral: lo presente era la realidad del sueño de la niñez y de esto gozaba ( $R$, t. 1, cap. 1, p. 109).

El sueño se lleva a cabo en un lugar elevado ( en una cumbre), siempre desde arriba, un sueño que ya se había hecho realidad. La ambición de niño se describe por medio de la repetición del sustantivo horas y el valor imperfectivo de la construcción de gerundio, pasaba soñando despierto. De este predicativo (despierto) se infiere el carácter material de sus sueños: En la gran ciudad colocaba él maravillas que halagaban el sentido y llenaban la soledad de su espíritu inquieto, con los que experimentaba placer. El sueño permite la identificación entre niño y Magistraly la consecuencia lógica de su placer de ahora: lo presente era la realidad del sueño de la niñez y de esto gozaba. Y gozaba a través de un sentimiento de dominación, que ejercía desde la torre (véase $R, \mathrm{t} .1$, cap. 1 , pp. 110-111). Clarín describe minuciosamente Vetusta desde la torre: desde allí arriba se divisa toda la ciudad. Y es desde allí, donde el Magistral veía a sus pies el barrio linajudo $(R, \mathrm{t} .1$, cap. 1 , p. 110). Para ello se servía del catalejo:

Emociones semejantes ocupaban su alma mientras el catalejo, reflejando con vivos resplandores los rayos del sol, se movía lentamente pasando la visual de tejado en tejado, de ventana en ventana, de jardín en jardín ( $R$, t. 1, cap. 1, p. 109).

Cuando el Magistral saca el catalejo, define la escena. Según F. Durand, aquí funciona "un espejismo complejo en que la realidad se deforma, esperpénticamente, a través del humor, la ironía, la parodia y la seriedad poética y psicológica"30. El placer por 
la dominación se describe mediante el operador argumentativo lentamente y la iteración de los sustantivos tejado, ventana y jardín. De este modo, la dominación es total. Para José Manuel González Herrán, en esta panorámica general es donde la lectura cinematográfica de La Regenta encuentra su momento más adecuado:

si el cine es mirada, perspectiva localizada y en movimiento, a través de una lente -el ojo de la cámara- no hay símil más adecuado que ese catalejo del canónigo, a través del cual el lector -convertido ahora como De Pas en voyeur-divisa la ciudad a sus pies ${ }^{31}$.

Por otra parte, véase la relación tan íntima entre torre y Fermín, en cuanto a la torre como puesto de observación y Fermín, el sujeto observador:

Desde un punto de vista técnico surge con toda claridad el punto de observación adoptado (torre de la Catedral) y el sujeto contemplador (don Fermín), ofreciendo la originalidad de que la aparente inmovilidad del magistral es alterada por la constante movilidad del catalejo que permite a su vez el acercamiento de lo contemplado ${ }^{32}$.

A través del catalejo, el Magistral nos descubre una panorámica social, que es la de Clarín y "no sólo representa una síntesis de las ambiciones de Fermín, sino que en ella se contiene un análisis de los diversos sectores sociales que componen la colectividad ovetense" 33 . Y tanto la ambición como la dominación producían en su espíritu un placer material (véase $R, \mathrm{t}$. 1, cap. 1, pp. 107-108). La ambición ya era una característica de su niñez (tiempo pasado), mientras que la dominación es un instinto del presente. La suma de ambición y dominación le producían placer material, que se identifica con consuelo de su alma:

placer material (ambición + dominación) = consuelo de su alma.

Se aúnan en la descripción lo material y lo espiritual. Sin embargo, se trata de una aparente ambigüedad, ya que se obtiene una explicatura clara de 'materia'. Asimismo, la fusión de lo material con lo espiritual continúa bajo el signo de la ironía ${ }^{34}$ :

31 "Lectura cinematográfica de La Regenta", en Clarin y "La Regenta" en su tiempo..., p. 476.

32 Rosario Martínez Galán, "La descripción del escenario en $L a$ Regenta", en Clarin y "La Regenta" en su tiempo..., p. 572.

${ }_{33}$ J. ORTEGA, art. cit., p. 328.

34 Por medio de la ironía llega a la sátira: "Alas se ha convencido de que a la masa deben inculcársele las ideas de modo que la diviertan, de modo 
El Magistral volvía el catalejo al Noroeste, allí estaba la Colonia, la Vetusta novísima, tirada a cordel, deslumbrante de colores vivos con reflejos acerados; parecía un pájaro de los bosques de América, o una india brava adornada con plumas y cintas de tonos discordantes. Igualdad geométrica, desigualdad, anarquía cromáticas. En los tejados todos los colores del Iris como en los muros de Ecbátana; galerías de cristales robando a los edificios por todas partes la esbeltez que podía suponérseles; alardes de piedra inoportunos, solidez afectada, lujo vocinglero. La ciudad del sueño de un indiano que va mezclada con la ciudad de un usurero o de un mercader de paños o de harinas que se quedan y edifican despiertos. Una pulmonía posible por una pared maestra ahorrada; una incomodidad segura por una fastuosidad ridícula. Pero no importa, el Magistral no atiende a nada de eso; no ve allí más que riqueza; un Perú en miniatura, del cual pretende ser el Pizarro espiritual ( $R$, t. 1, cap. 1, pp. 114-115).

El operador argumentativo allí pone de manifiesto el lugar concreto de la materia: la riqueza y la metáfora cargada de ironía (Pizarro espiritual). Esta metáfora es un ejemplo más de la fusión materia-espíritu tan característica de la descripción clariniana. Dicha fusión sólo puede explicarse por la ironía. La explicatura queda reducida a 'lo material'.

Por último, hay que hacer notar que la ambigüedad se mantiene hasta el final de la novela: Afortunadamente él tenía arte para todo: sabría ser místico hasta donde hiciera falta, perderse en las nubes sin olvidar la tierra $(R$, t. 2, cap. 21, p. 205). Es aquí, al final de la novela, donde se comprueba la constante de este personaje: era materia, aunque aparentaba espíritu.

\section{Conclusiones}

La torre de la Catedral adquiere importancia textual en la novela por lo que simboliza y por su relación con Fermín de Pas; son dos personajes cercanos. Clarín describe la torre y, a continuación, al Magistral. Al detallar la torre, el autor establece un paralelismo semántico y pragmático con Fermín de Pas. En las descripciones,

que la distraigan, para que pueda tragarlas sin sentir. Y por eso escribe casi siempre en broma; broma sólo aparente y superficial, por supuesto, que si en ellas se ahonda, suele encontrársele a menudo alguna más filosofía que a muchas estupideces respetadas por el vulgo como cosa seria. Por eso su lección es siempre la lección de la sátira" (Antonio Sotillo, "El hombre: anécdotas", en Clarín y "La Regenta" (1884-1984), p. 37). 
tanto de la torre como del Magistral, se aúna semánticamente lo físico con lo espiritual. Esta contraposición entre materia y espíritu cohesiona y estructura toda la descripción clariniana. La torre de la Catedral es, en realidad, el primer personaje de la novela: la personificación es reiterativa a lo largo de toda la descripción.

$\mathrm{Al}$ comienzo de este estudio, diferentes investigadores pusieron de manifiesto que tanto la torre como Fermín son símbolos disémicos. Sin embargo, resulta más acertada la afirmación de que la torre de la Catedral es un símbolo disémico sólo en la primera parte de la novela; mientras que en Fermín de Pas la ambigüedad se mantiene hasta el final de la obra. Téngase en cuenta que ésta es una consideración semántica, porque pragmáticamente no hay ambigüedad alguna.

La torre de la Catedral es el símbolo de la Iglesia como institución en abstracto; mientras que Fermín de Pas es el símbolo del estado eclesiástico, hijo de esa institución, algo concreto: todo es materia, con apariencia de espíritu. Sin explicaturas, el discurso es ambiguo, pero lo dicho desemboca en materia. Para ello, Clarín se ha servido de la ironía y la sátira. En La Regenta, la crítica más feroz hecha a la Iglesia es la que se sustenta en estos dos personajes.

Es evidente que, para las descripciones de la torre y Fermín, Clarín se vale de diferentes actos de habla ilocutivos, de gran fuerza pragmática, que tienen una clara finalidad perlocutiva, presente en la implicatura de 'remover las conciencias de los responsables de la institución eclesiástica'. Es claro que esta finalidad comunicativa se relaciona con la circunstancia histórica y literaria de su autor. Téngase en cuenta que la Revolución de 1868 no produjo únicamente una radical transformación política: penetró en los espíritus. Como señala Clarín, "la religión y la ciencia que habían sido aquí ortodoxas en los días de mayor libertad política, veíanse por vez primera en tela de juicio"35.

SALVAdor López Quero

Universidad de Córdoba

35 "El libre examen y nuestra literatura presente", en Clarín y "La Regenta" (1884-1984), p. 24. 